\title{
Spawning Environment of Chum Salmon in the Coastal Rivers on the Pacific Side of Northern Japan
}

\author{
Satoki Oba ${ }^{1}$, Tatsuya Kawakami ${ }^{2}$, Yuki Minegishi ${ }^{3}$, and Jun Aoyama ${ }^{1}$ \\ ${ }^{1}$ International Coastal Research Center, Atmosphere and Ocean Research Institute, The University of Tokyo, \\ Akahama 1-19-8, Otsuchi, Iwate 028-1102, Japan \\ ${ }^{2}$ Faculty of Fisheries Science, Hokkaido University, 3-1-1, Minato-cho, Hakodate, Hokkaido 041-8611, Japan \\ ${ }^{3}$ Center for Earth Surface System Dynamics, Atmosphere and Ocean Research Institute, The University of Tokyo, \\ Akahama 1-19-8, Otsuchi, Iwate 028-1102, Japan
}

Keywords: chum salmon, wild fish, natural spawning, spawning redds, environment

The environment in the spawning redds such as water temperature and dissolved oxygen is important for the growth and survival of chum salmon (Oncorhynchus keta) during their early life stages (Bjornn and Reiser 1991; Bloomer 2016). However, little attention has been paid to natural spawning and the spawning habitat of chum salmon on the Pacific side of northern Japan (the Sanriku Coast), which constitutes the southern edge of the specific range. This is because most adults returning to Japanese waters, including the Sanriku Coast, have been considered to be hatchery-origin due to the intensive implementation of the stock enhancement program. Recently, the possible importance of the wild population for the entire Japanese stock has been reported (Morita et al. 2013; Aruga et al. 2014). Moreover, the natural spawning of chum salmon on the Sanriku Coast has been observed after Great East Japan Earthquake occurred in 2011 (Aoyama 2017; Minegishi et al. 2021). We investigated, as the first step, the spawning environment of chum salmon in the Kozuchi and Unozumai Rivers on the Sanriku Coast, Japan.

The study area was a range of about $230 \mathrm{~m}$ in both rivers, where the spawning redds of chum salmon were observed most abundantly during the spawning season in each river. The field surveys were carried out in the Kozuchi River on 24 and 25 December 2019, and in the Unozumai River on 19 December 2019. Water temperature, dissolved oxygen (DO), and electric conductivity (EC) in the riverbed and surface water were measured at 18 and 10 spawning redds and 12 and 10 non-spawning sites in the former and latter rivers, respectively. Vertical hydraulic gradient (VHG) was simultaneously measured with a piezometer. Gravel size was visually described following the Udden-Wentworth grain size scale.

In the Kozuchi River, the median water temperature, DO, EC and VHG in the spawning redds were 10.0 (9.1$11.1)^{\circ} \mathrm{C}, 8.0(5.8-10.1) \mathrm{mg} / \mathrm{L}, 81.9(71.6-98.1) \mathrm{mS} / \mathrm{cm}, 0.018(0.006-0.020)$, while those in the Unozumai River were $10.5(7.4-11.6)^{\circ} \mathrm{C}, 7.6(6.7-10.2) \mathrm{mg} / \mathrm{L}, 91.5(85.4-96.9) \mathrm{mS} / \mathrm{cm}, 0.013(0.000-0.028)$, respectively. The spawning redds were placed predominantly in the $2-60 \mathrm{~mm}$ size gravel beds in both rivers. No statistically significant difference was observed in the environmental parameters for the spawning redds between the two rivers. At the non-spawning sites, however, the temperatures of the surface water $\left(8.8^{\circ} \mathrm{C}\right)$ and the riverbeds $\left(10.7^{\circ} \mathrm{C}\right)$ of the Kozuchi River were significantly higher than the Unozumai River $\left(5.5^{\circ} \mathrm{C}\right.$ for surface and $8.5^{\circ} \mathrm{C}$ for the riverbeds), while DO of the riverbeds in the Kozuchi River $(5.2 \mathrm{mg} / \mathrm{L})$ was significantly lower than the Unozumai River (7.4 $\mathrm{mg} / \mathrm{L}$ ). As the groundwater is generally characterized by lower DO compared to the surface water (Malard and Hervant 1999), the upwelling of groundwater was suggested to be more abundant in the Kozuchi River than in the Unozumai River. In the Kozuchi River, the DO and EC in the spawning redds were significantly higher and lower than those in the non-spawning sites, respectively, which suggests that the groundwater upwells more abundant in the non-spawning sites than in the spawning redds. On the other hand, in the Unozumai River, no statistically significant differences were observed in any environmental parameters between the spawning redds and nonspawning sites.

The present study revealed the environment of the spawning redds in the rivers on the Sanriku Coast:water temperature and DO in the spawning redds were about $10^{\circ} \mathrm{C}$ and $8.0 \mathrm{mg} / \mathrm{L}$, respectively. In the Kozuchi River, it was found that the rich upwellings of the groundwater distribute patchily in the survey area. In contrast, in the Unozumai River, although the abundance of the groundwater upwelling appeared to be relatively less compared to the Kozuchi River, the groundwater upwells uniformly over the study area. So, chum salmon adults selectively spawn at the oxygen-rich sites where the groundwater upwells moderately in the Kozuchi River, while no selectivity is exhibited relative to the groundwater upwelling in the Unozumai River. The present study suggests that, in the Sanriku coastal rivers, the water temperature is a primary factor for chum salmon adults to select appropriate spawning sites, but the upwelling of the groundwater is likely less important when a suitable water temperature is available. 


\section{REFERENCES}

Aoyama, J. 2017. Natural spawning of chum salmon (Oncorhynchus keta) within a hatchery stock enhancement program: a case in the Otsuchi River at the Sanriku coast. Coast. Mar. Sci. 40: 1-6.

Aruga, M., K. Morita, T. Suzuki, N. Sato, M. Okamoto, and K. Ohkuma. 2014. Evaluation of population viability of wild chum salmon (Oncorhynchus keta) in the Toyohira River, Sapporo metropolitan watershed, Japan. Nippon Suisan Gakkaishi 80(6): 946-955.

Bjornn, J.R., and D.W. Reiser. 1991. Habitat requirements of salmonids in streams. In Influence of Forest and Rangeland Management on Salmonids Fishes and Habitats. Edited by W.R. Meehan. Spec. Publ. Am. Fish. Soc. 19: 83-138.

Bloomer, J. 2016. Deoxygenated groundwater upwelling in the Atlantic salmon incubation zone: Implications for embryonic survival and opportunity for adaptation. Ph.D. thesis, Univ. Southampton. 52 pp.

Malard, F., and F. Hervant. 1999. Oxygen supply and the adaptations of animals in groundwater. Freshw. Biol. 41: $1-30$.

Minegishi, Y., T. Kawakami, and J. Aoyama. 2021. Wild population and natural spawning of chum salmon in the Kozuchi River on the Sanriku Coast, Japan. N. Pac. Anadr. Fish Comm. Tech. Rep. 17: 174-175. (Available at https://npafc.org)

Morita, K., S. Takahashi, K. Ohkuma, and T. Nagasawa. 2013. Estimation of the proportion of wild chum salmon (Oncorhynchus keta) in Japanese hatchery rivers. Nippon Suisan Gakkaishi 79(2): 206-213. 